\title{
A Case Study on Lecturers' Motivation Under the Self-Determination Theory
}

\author{
Ma Wen-ying, Liu Xi \\ Changchun University, Changchun, China
}

\begin{abstract}
This study investigates the motivation of lecturers in a Chinese university. Recent studies have shown that low morale and job dissatisfaction are significant problems identified in lecturers in Chinese universities. Low staff morale is likely to be associated with less effective teaching and poor student learning outcomes. Although the problem is acknowledged, there has been limited research to understand the underlying contributing factors. To address this, a survey was adopted and implemented at a large regional university in Northern China. The participants in the study were 100 lecturers from two colleges at this university. The study found that in contrast to previously reported studies, lecturers in this institution were in general intrinsically motivated in teaching. The contextual factors, such as the reward system and leadership. were significant in regulating lecturers' motivation to teach. The findings are significant for leaders in higher education who need to implement policies that foster effective work environments.
\end{abstract}

Keywords: case study, teaching motivation, Self-Determination Theory (SDT)

\section{Introduction}

The slogan "Education needs modernization and modernization needs education" (Ross, 1991, p. 67) reflects the dilemma facing China as it undergoes a rapid transition from a largely agrarian society to a modern globalised economy. Accordingly, education has become strongly linked to the economy.

Teachers are the key parts in a university. The attributes expected of a qualified teacher are various and include a suitable personality, good teaching skills, research competence, rich knowledge, good skills for classroom management and communication, and professional dedication (Shu, 2005). Given these expectations, many university administrators have speculated that lecturers are struggling to meet the demands placed on them by their institutions, as well as the demands placed on them by their daily lives in contemporary China. Concerns have been expressed about the commitment of teachers, with the perception that in the context of higher education, teachers are not sufficiently dedicated to their teaching jobs (Lu, 2004). As recently as 2008, Gao claimed that lecturers' professional vulnerability might be in fact worsen before it can improve on the Chinese mainland in the near future, and the factors that contributed to dissatisfaction were factors related to pay and promotion (as cited in $\mathrm{Yu}, 2010$ ).

An extensive analysis of the literature in relation to the problem of academic commitment, however, has yielded very little empirical research. Only one study has been identified, which explicitly examines the

Ma Wen-ying, Ph.D., associate professor, School of Foreign Languages, Changchun University.

Liu Xi, M.A., lecturer, School of Foreign Languages, Changchun University. 
motivation and engagement of teachers in Chinese higher education institutions ( $\mathrm{Lu}, 2004)$. In this study, $\mathrm{Lu}$ investigated intrinsic and extrinsic motivation among 80 lecturers in Zhejiang Province. The results showed that $80 \%$ of the teachers were dissatisfied with their jobs and $50 \%$ said that they would not be lecturers again if they had a choice. Furthermore, $30 \%$ of the lecturers were trying to change their profession by engaging in further graduate education. The lecturers reported that increased pressure for academic performance, a lack of challenge, no sense of self-growth, no sense of self-efficacy, and limited work autonomy were having a negative impact on their teaching. The study concluded that there was a serious crisis in motivation among English language lecturers in China (Lu, 2004, pp. 60-61).

Given this apparent crisis among teachers in higher education in China, the present study has adopted a questionnaire to investigate the motivation of lecturers towards teaching and working in a Chinese university. The study has utilised a survey to examine teachers' motivation, as well as some suggestions on enhancing lectures' motivation.

The notion of motivation, as in Oxford Dictionary of English, is a reason or reasons for acting or behaving in a particular way. Brophy (1985) defined motivation as "a theoretical construct used to explain the initiation, direction, intensity, and persistence of behavior, especially goal-directed behavior” (p. 3).

The usual meaning of motivation for the teacher is probably the interest that something generates in the students. A particular exercise, a particular topic, a particular song, may make the students appear involved in the class, to the teacher's delight. (Butler \& Shibaz, 2008, p. 454)

Self-Determination Theory (SDT) (Deci \& Ryan, 1985) categorises motivation into three broad types: amotivation, extrinsic motivation, and intrinsic motivation, and arranged in a continuum according to the levels of self-determination. In SDT, self-determination means the process of autonomy, which "refers to being the perceived origin or source of one's own behaviour" (Deci \& Ryan, 1985; Ryan \& Connell, 1989, p. 8). From lower to higher levels, motivation is designated as amotivation, external regulation, introjected regulation, identified regulation, integrated regulation, and intrinsic motivation (Ryan \& Connell, 1989).

Amotivation refers to a state in which there is resistance to engaging in an activity. Behaviour corresponding to this type of motivation is neither self-determined nor self-regulated. Extrinsic motivation refers to motivation to act that is largely driven by sources outside of the individual. Ryan and Connell (1989) divided extrinsic motivation into different types which they termed "regulations" (or the value underlying an action) and arranged these along a continuum (see Figure 1). In ascending order of level of self-determination, these are external regulation, introjected regulation, identified regulation, and integrated regulation.

External regulation is the least self-determined type of extrinsic motivation as it is reinforced by specific external rewards or punishment. External regulation is considered to control extrinsic motivation behaviour; it is promoted and maintained by the contingency but will disappear when the rewards and punishments are withdrawn. Introjected regulation involves the process in which external demands become a strategy to generate an internal response. Thus, to make sure they perform an activity, they place pressure on themselves through internal reinforcement, such as shame or guilt. Identified regulation, a more self-determined type of regulation, exists when an individual's motivated behaviour is consciously driven by the individual's values and goals. Because this regulation is so closely identified with self, motivation can be explained as a way to maintain particularly motivated behavior, and thus, achieve high quality performance. Integrated regulation is the fullest, most complete type of self-determined regulation across the continuum of extrinsic motivation. This 
type of regulation is driven by a strong sense of self, and is likened to intrinsically motivated behaviour.

The last type of motivation in SDT is intrinsic motivation. Intrinsic motivation refers to disposition to engage in an activity for the pleasure and satisfaction that is inherent in the activity (Deci \& Ryan, 1985).

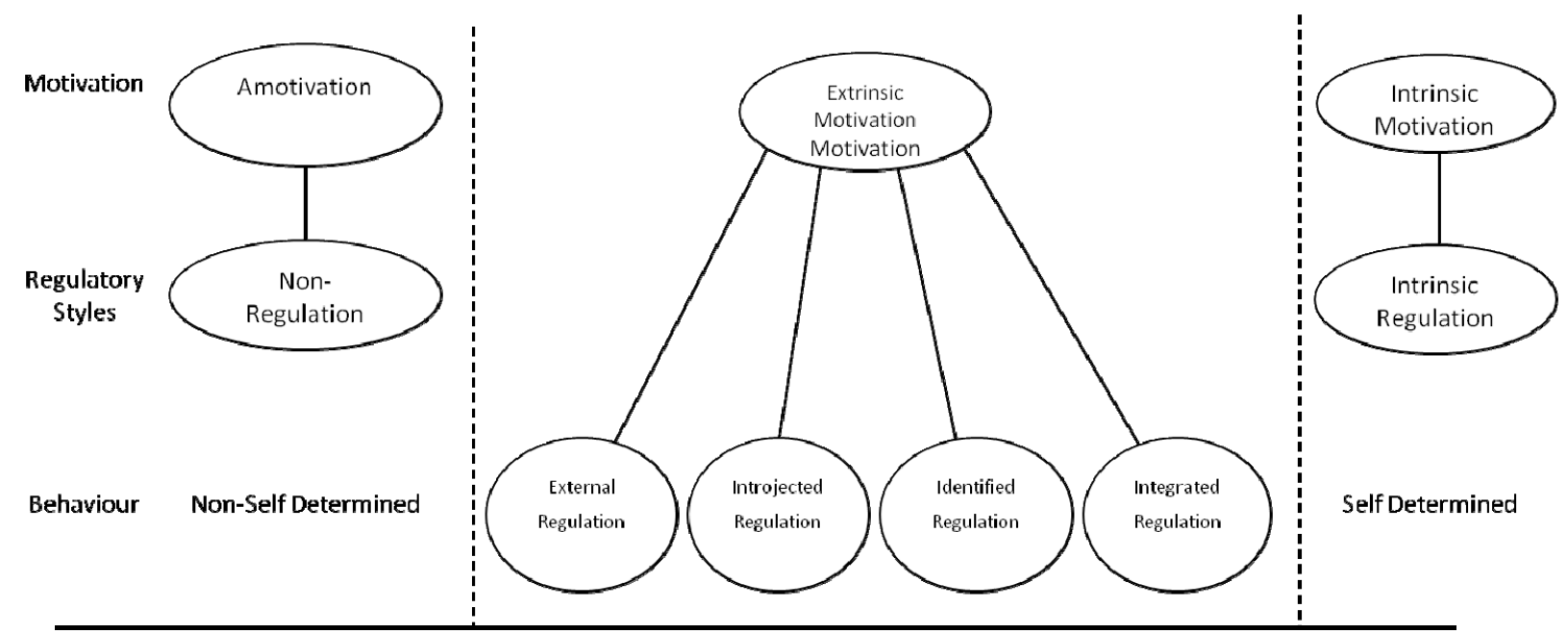

Figure 1. Self-determination continuum showing types of motivation with their regulatory styles (Ryan \& Deci, 2000, p. 72).

\section{Method}

\section{Participants}

The present study tries to investigate the types of motivation in a Chinese university. The participants in the study were 100 lecturers from two colleges in a large university in China. All of the lecturers were responsible for teaching and they agreed to participate in the study.

\section{Instruments}

This study utilized the questionnaire Work Tasks Motivation Scale for Teachers-Teaching (WTMST-T). The WTMST-T was developed by Fernet, Senecal, Guay, Marsh, and Dowson in 2008. In the present study, this scale was used to test lecturers' motivation (amotivation, extrinsic motivation, and intrinsic motivation).

There are 15 items in the questionnaire and each item is repeated for each of six tasks that relate to teaching functions. These tasks are class preparation, teaching, evaluation of students, class management, administrative tasks, and complementary tasks. Thus, the full instrument provides a measure of motivation on each of these tasks. Given the aim of this study, investigating the types of teaching motivation of lecturers in a Chinese university, the present study only used the scale on teaching (WTMST-T). Participants respond to the items using a 7-point type scale ranging from 1-"Does not correspond at all" to 7-“Correspond completely." The reported Cronbach's $\alpha$ values ranged from 0.83 to 0.96 (Mean $=0.92$ ) for intrinsic motivation, 0.72 to 0.89 $($ Mean $=0.82)$ for identified regulation, 0.79 to $0.89($ Mean $=0.85)$ for introjected regulation, 0.64 to 0.87 $($ Mean $=0.76)$ for external regulation, and 0.75 to 0.81 (Mean $=0.77$ ) for amotivation (Fernet et al., 2008).

Chinese versions of the research questionnaires were not available, so it was necessary to conduct a rigorous three-step translation process in preparation for the pilot study. The five questionnaires were translated from English to Mandarin Chinese and then back-translated to English (Chow, Harrison, Lindquist, \& Wu, 1997). The forward and backward translations were employed to produce equivalency between the original language (English) and the target language (Chinese) on content. 


\section{Results}

The research question posed in this study concerned the types of motivation evident among the lecturers in the research site university. The participants were asked to complete the WTMST-T on a 7-point Likert scale. Five types of motivation are measured, namely, intrinsic motivation, identified regulation, introjected regulation, external regulation, and amotivation. The participants respond to each question on a 7-point Likert scale. Accordingly, each type of motivation has a maximum possible score of $21(7 \times 3)$ and a neutral median is $12(4 \times 3)$.

A frequency analysis of data yielded by the WTMST-T indicated that $52.5 \%$ of the participants obtained scores at or above the neutral median score of 12 for the intrinsic motivation scale. Furthermore, $52 \%$ obtained scores at or above the neutral median score of 12 for identified regulation (see Table 1). Earlier in this chapter, descriptive statistics analysis on WTMST-T revealed Cronbach's $\alpha$ for intrinsic motivation and identified regulation. Therefore, the scales were internally consistent (see Table 1). On the basis of literature, this finding indicated that the types of motivation which existed in the lecturers were marginally intrinsic motivation and identified regulation.

Table 1

Descriptive Statistics in WTMST-T

\begin{tabular}{lllllrr}
\hline Scale & Cronbach's $\alpha$ & Mean & $S D$ & Skewness & Kurtosis & Range \\
\hline Intrinsic motivation & 0.84 & 16.51 & 4.17 & -0.51 & -0.65 & $4-21$ \\
Introjected regulation & 0.15 & 7.86 & 3.24 & 3.17 & 0.58 & 0.03 \\
External regulation & 0.16 & 11.13 & 3.90 & -0.16 & $3-21$ \\
Identified regulation & 0.67 & 15.25 & 3.73 & 0.85 & -0.75 & -0.07 \\
Amotivation & 0.46 & 6.67 & & $3-17$ & \\
\hline
\end{tabular}

\section{Conclusion}

The present study did research on the types of motivation of lecturers in a Chinese university. According to the SDT, there are three types of motivation: amotivation, extrinsic motivation, and intrinsic motivation. SDT argues that human motivation is formed in a social context. SDT emphasises the influence of social culture and context on motivation and behaviour. The participants of the study are 100 lecturers in a Chinese university. A survey was delivered to the participants. The finding of the present study was that intrinsic motivation and identified regulation were the predominant forms of motivation. This indicates that lecturers at the research site university were generally internally motivated. Participants in the present study defined their teaching on the basis of interests and self-endorsed values; therefore, their motivation to teach was measured against their personal tendencies towards intrinsic motivation and well integrated extrinsic motivation, or identified regulation. Both types of motivation were evident in the population, although a higher mean score indicated that intrinsic motivation was more dominant. However, the findings are unlike those of Lu (2004), which found that $80 \%$ of the participants were dissatisfied with their lecturing jobs, $50 \%$ would not be lecturers again if they had a choice, and 30\% were trying to change their profession by engaging in further graduate education. Specifically, this study found that $52.2 \%$ of the lecturers had intrinsic motivation to teach and $50 \%$ had identified regulation to teach. The difference between the two studies may be that Lu's (2004) study was a survey study investigating a phenomenon, while the present study was a case study. 
Some suggestions on enhancing the motivation of lecturers will be presented according to the results of the research. These are related with school policies on the aspects of the reward system and leadership.

Rewards are management tools that hopefully contribute to an institute's effectiveness by influencing individual or group behaviour (Lawler \& Cohen, 1992, p. 8). Rewards are defined as the "deliberate utilisation of the pay system as an essential integrating mechanism through which the efforts of various sub-units or individuals are directed towards the achievement of an organisation's strategic objectives" (Gomez-Mejia \& Balkin, 1992, p. 58). Although some research proposed that rewards could undermine productivity and performance (Denning, 2001), Cameron and Pierce (1997) stated that rewards could be used effectively to enhance motivation when they are offered to people for completing work or for attaining or exceeding specified performance standards. Cameron and Pierce further postulated that rewards increase performance and interest when they are made contingent on quality or performance or are given for meeting clear standards of performance; and delivered for high effort and activity. Therefore, in the university, careful arrangement of rewards, which are given for mastering each component of a complex skill, or delivered for high effort and activity, can enhance lecturers' interest and level of performance; consequently enhancing lecturers' intrinsic motivation.

The Higher Education Law (Chinese Communist Party, 1998) legitimised the leadership in university management. In Chinese universities, leadership comprises a president academically selected and an executive vice president chosen by the Communication Party. This unique combination of academic and political governance arrangements sometimes creates administrative tension and reduces self-governance by the academic community (Altbach, 2000). In recent years, China has begun to follow an American academic leadership model, with leadership in universities being strengthening (Min, 2004). Thus, more authority has been given to departmental chairs and other administrators to implement a faculty responsibility system in research and teaching.

Findings from the present study also implied that the style of leadership had a considerable impact on their work motivation. Leaders within higher education institutions need to display the following attributes: be open to and encourage the creativity of staff, be team-oriented (i.e., be ready to rely on help from others), be able to listen, practice coaching (i.e., give advice and motivate), demonstrate accountability (i.e., take personal ownership and support the changes), and show appreciation (i.e., recognise and reward the employees' effort in relation to the changes) (Galpin, 1996).

In order to create a culture that is motivating and in which employees' opinions are valued, leaders need to be open and encouraging of employee input and participation. Employee participation in policy-making is positively associated with organisational effectiveness and job satisfaction (Sagie \& Koslowski, 1994). In turn, organisational effectiveness and job satisfaction have been reported to have meaningful effects on the attitudes and autonomous motivation of employees (Locke \& Schweiger, 1979). This suggests that the autonomous motivation of lecturers would likely be enhanced by a more open style of leadership that encouraged authentic communication, teamwork, professional development, participation, accountability, and recognition of successful teaching and learning.

\section{References}

Altbach, P. G. (2000). The changing academic workplace: Comparative perspectives. Chestnut Hill, M.A.: Boston College Centre for International Higher Education.

Brophy, J. (1985). Motivating students to learn. Boston, M.A.: McGraw-Hill. 
Butler, R., \& Shibaz, L. (2008). Achievement goals for teaching as predictors of students' perceptions of instructional practices and students' help seeking and cheating. Learning and Instruction, 18, 453-467.

Cameron, J., \& Pierce, D. W. (1997). Rewards, interest and performance: An evaluation of experimental findings. American Compensation Association Journal, 6, 4. Retrieved from http:// zigonperf.com/PMNews/reward_and_perf_research.html

Chinese Communist Party. (1998). Higher education law of the People's Republic of China. Retrieved from http://www.moe.gov.cn/

Chow, C. W., Harrison, P., Lindquist, T., \& Wu, A. (1997). Escalating commitment to unprofitable projects: Replication and cross-cultural extension. Management Accounting Research, 8, 347-361.

Deci, E. L., \& Ryan, R. M. (1985). Intrinsic motivation and self-determination in human behaviour. New York, N.Y.: Plenum Press.

Denning, S. (2001). Incentives for knowledge management. Incentives for knowledge management_Incentives for knowledge sharing 2000. Retrieved from http://www.stevedening.com/incentives_knowledge_management.html

Fernet, C., Senecal, C., Guay, F., Marsh, H., \& Dowson, M. (2008). The work tasks motivation scale for teachers. Journal of Career Assessment, 16, 256-279.

Galpin, T. J. (1996). The human side of change: A practical guide to organization redesign. San Francisco, C.A.: Jossey-Bass, Inc..

Gomez-Mejia, L. R., \& Balkin, D. B. (1992). Compensation, organizational strategy and firm performance. Cincinnati, O.H.: South-Western Publishing.

Lawler, E. E., \& Cohen, S. G. (1992). Designing pay systems for teams. American Chiropractic Association Journal, 1, 6-19.

Locke, E. A., \& Schweigner, D. M. (1979). Participation in decision making: One more look. Research in Organisational Behaviour, 1, 265-339.

Lu, H. R. (2004). Zhimian daxue yingyu jiaoshi jiaoxuedongji (Facing English lecturers' teaching motivation). Education and Occupation, 30, 60-61.

Min, W. (2004). Chinese higher education: The legacy of the past and the context of the future. In P. G. Altbach, \& T. Umkoahi (Eds.), Asian universities: Historical perspectives and contemporary challenges (pp. 53-84). Baltimore, M.D.: Johns Hopkins University Press.

Ross, H. (1991). The "crisis" in Chinese secondary schooling. In I. Epstein (Ed.), Chinese education: Problems, policies and prospects. New York, N.Y.: Garland.

Ryan, R. M., \& Connell, J. P. (1989). Perceived locus of causality and internalization: Examining reasons for acting in two domains. Journal of Personality and Social Psychology, 57, 749-761.

Ryan, R. M., \& Deci, E. L. (2000). Self-Determination Theory and the facilitation of intrinsic motivation, social development, and well-being. American Psychologist, 55, 68-78.

Sagie, A., \& Koslowski, M. (1994). Organisational attitudes and behaviours as a function of participation in strategic and tactical change decisions: An application of path-goal theory. Journal of Organisational Behaviour, 15, 37-47.

Shu, D. F. (2005). China needs foreign language teaching theories with Chinese characteristics. Foreign Language World, 6, 2-7.

Yong, Z., \& Campbell, K. P. (1995). English in China. World English, 14, 377-390.

Yu, X. Y. (2010). Job satisfaction of university academics in China. Retrieved June 10, 2012, from http://hdl.handle.net/10443/940 